\title{
Feto-maternal Outcomes of Emergency Caesarean Section following Residential Posting at Dhading District Hospital
}

\author{
Pramod Kattel ${ }^{1}$ \\ 'Department of Obstetrics and Gynaecology, Kathmandu National Medical College, Kathmandu, Nepal.
}

\section{ABSTRACT}

Introduction: Caesarean section is a commonly performed major obstetric surgery to deliver baby under certain indications which may be maternal or fetal. If performed timely, it is helpful to save the life of mother and fetus and if not, it increases both maternal and fetal risks.

Methods: A hospital based descriptive cross-sectional study was conducted at Dhading district hospital from $17^{\text {th }}$ October 2016 to $17^{\text {th }}$ October 2017. Total of 41 patients undergoing emergency caesarean section meeting the selection criteria were included.

Results: The incidence of emergency caesarean section was 41 (5.5\%). Most common indication for caesarean delivery was fetal distress in $12(29.3 \%)$ followed by failed induction and cephalopelvic disproportion each accounting $6(14.6 \%)$ cases. The least common causes being chorioamnionitis and cord prolapse in 1 (2.4\%). Regarding perinatal outcomes, $33(80.5 \%)$ babies delivered were of normal weight. Low Apgar score $(<7)$ at one minute was noted in $8(19.5 \%)$ cases. Neonatal resuscitation in the form of oxygen supplementation was required in $2(4.9 \%)$ cases whereas bag and mask ventilation was required in $5(12.2 \%)$ cases. Referral for neonatal intensive care unit admission was done in 6 $(14.6 \%)$ cases. There were three neonatal deaths.

Conclusions: Residential posting was fruitful to decrease feto-maternal morbidities and mortalities. Even to minimize the delay of treatment, government should provide adequate equipments and skilled man-power to run neonatal intensive care unit.

Keywords: caesarean section; district hospital; fetal mortality; pregnancy outcome; residency.

\section{INTRODUCTION}

Caesarean section (CS) represents the most significant obstetric operative intervention. ${ }^{1}$ CS is defined as delivery of fetus through incision in abdominal and uterine wall after fetal viability. ${ }^{2-4}$ The ideal CS rate is between $10-15 \% .{ }^{5} \mathrm{CS}$ rate in Nepal has increased from $5 \%$ in 2011 to $9 \%$ in $2016 .{ }^{6}$ Rate of CS has increased worldwide in recent years due to increased safety of procedure. ${ }^{1,4,7}$ Rise in CS rate has become a public health concern. ${ }^{3}$ Caesarean delivery is the marker for availability and use of obstetric services. ${ }^{8}$ Globally, CS has markedly improved maternal and fetal outcomes of pregnancy. ${ }^{1}$ Gestational age at CS and indications determine perinatal outcomes of emergency $\mathrm{CS}^{9}$

This article reflects the improved impact on maternal and fetal outcomes provided by residential posting and their importance in district hospitals to overcome the shortage of skilled man-power.

This study was conducted to evaluate the feto-maternal outcomes of emergency CS following community

Correspondence: Dr. Pramod Kattel, Department of Obstetrics and Gynaecology, Kathmandu National Medical College, Kathmandu, Nepal. Email: pramodkattel85@gmail.com, Phone: +977-9847088684. 
Kattel Feto-maternal Outcomes of Emergency Caesarean Section following Residential Posting at Dhading District Hospital

posting of Doctor of Medicine (MD) - Obstetrics and Gynaecology (OBG) Residents.

\section{METHODS}

A hospital based descriptive cross-sectional study was conducted at Dhading district hospital from $17^{\text {th }}$ October 2016 to $17^{\text {th }}$ October 2017. Permission for data collection was taken from hospital authority. All 41 patients undergoing CS by the MD-OBG Residents under community posting scheme of National Academy of Medical Sciences (NAMS) during the study period were included in the study. Data were collected by reviewing the hospital records. Operation theatre register and operative notes were checked in addition to admission sheets and out-patient and in-patient registers to get information on maternal age, parity, number of antenatal checkup (ANC) visits, gestational age at CS, indication of CS, maternal complications, presentation of baby, birth weight of baby, sex of baby delivered, interval between accomplishment of CS and start of breastfeeding, Apgar score at one minute, requirement of neonatal resuscitation or not and mode in required cases, need for neonatal intensive care unit (NICU) referral, neonatal injury during CS, neonatal sepsis, neonatal seizure, neonatal death (NND) and its relation to birth and duration following birth. Post-mortem of neonates that died was not done. To describe variables, statistical tools of absolute numbers, percentages, mean, rate and ratio are used. The data obtained were analyzed with statistical package for social sciences (SPSS), version 16 and presented in tables.

\section{RESULTS}

The prevalence of emergency CS was $5.5 \%$ (41 of 752 deliveries). Almost half that is $19(46.4 \%)$ cases of the CS occurred in maternal age group of $20-25$ years with mean age of 23 years. CS in primigravida accounted in $27(65.9 \%)$ cases. Booked cases undergoing CS were $28(68.3 \%)$. The commonest gestational age for CS was $39-41$ weeks in 20 (48.7\%) with mean gestational age of 40.6 weeks (Table 1 ).

\begin{tabular}{|lc|}
\hline \multicolumn{2}{|l|}{ Table 1. Maternal characteristics. } \\
\hline Characteristics & $\mathbf{n ~ ( \% )}$ \\
1.Maternal age (in years) & \\
$<20$ & $9(22 \%)$ \\
$20-25$ & $19(46.4 \%)$ \\
$25-30$ & $8(19.5 \%)$ \\
$30-35$ & $3(7.3 \%)$ \\
$35-40$ & $1(2.4 \%)$ \\
$\geq 40$ & $1(2.4 \%)$ \\
$2 . P a r i t y$ & \\
\hline
\end{tabular}

\begin{tabular}{|c|c|}
\hline Primigravida & $27(65.9 \%)$ \\
\hline Multipara (1-3) & $11(26.8 \%)$ \\
\hline Grandmultipara $(\geq 4)$ & $3(7.3 \%)$ \\
\hline \multicolumn{2}{|l|}{ 3. ANC visits } \\
\hline Unbooked & $13(31.7 \%)$ \\
\hline Booked & $28(68.3 \%)$ \\
\hline 1 visit & $7(17.1 \%)$ \\
\hline $2-3$ visits & $6(14.6 \%)$ \\
\hline$\geq 4$ visits & $15(36.6 \%)$ \\
\hline \multicolumn{2}{|c|}{ 4.Gestational age at CS } \\
\hline$<37$ & $2(4.9 \%)$ \\
\hline $37-39$ & $4(9.8 \%)$ \\
\hline $39-41$ & $20(48.7 \%)$ \\
\hline $41-42$ & $8(19.5 \%)$ \\
\hline$\geq 42$ & $7(17.1 \%)$ \\
\hline
\end{tabular}

Most common indication for CS was fetal distress in 12 $(29.3 \%)$ followed by failed induction and cephalopelvic disproportion (CPD) each accounting for 6 (14.6\%) cases. The least common identified causes were chorioamnionitis and umbilical cord prolapse each accounting for $1(2.4 \%)$ case (Table 2 ).

\begin{tabular}{|lc|}
\hline \multicolumn{2}{|l|}{ Table 2. Indications of caesarean section. } \\
\hline Indications & $\mathrm{n}(\%)$ \\
Abnormal presentation & $3(7.3 \%)$ \\
Cephalopelvic disproportion & $6(14.6 \%)$ \\
Chorioamnionitis & $1(2.4 \%)$ \\
Cord prolapse & $1(2.4 \%)$ \\
Failed induction & $6(14.6 \%)$ \\
Fetal distress & $12(29.3 \%)$ \\
Maternal distress & $2(4.9 \%)$ \\
Non-progress of labor & $4(9.8 \%)$ \\
Obstructed labor & $2(4.9 \%)$ \\
Oligohydramnios & $2(4.9 \%)$ \\
Prolonged IInd stage & $2(4.9 \%)$ \\
\hline
\end{tabular}

As many as $37(90.3 \%)$ cases were devoid of maternal complications and only two cases of postpartum haemorrhage $(\mathrm{PPH})$ required blood transfusion (BT) to maintain haemoglobin level $>8 \mathrm{gm} \%$. One case each was of puerperal pyrexia and wound infection (Table 3).

\begin{tabular}{|lc|}
\hline Table 3. Maternal complications. \\
\hline Maternal complications & $\mathbf{n}(\%)$ \\
None & $37(90.3 \%)$ \\
Postpartum haemorrhage & $2(4.9 \%)$ \\
Puerperal pyrexia & $1(2.4 \%)$ \\
Wound infection & $1(2.4 \%)$ \\
\hline
\end{tabular}


Kattel Feto-maternal Outcomes of Emergency Caesarean Section following Residential Posting at Dhading District Hospital

Regarding fetal outcomes, the most common presentation was vertex in $37(90.3 \%)$ cases and 33 babies $33(80.5 \%)$ delivered were of normal weight. In this study, $24(58.5 \%)$ newborns were male. Breast feeding was started within one hour of life in 36 (87.8\%) neonates (Table 4).

\begin{tabular}{|lc|}
\hline Table 4. Fetal characteristics. & \\
\hline Characteristics & $\mathbf{n}(\%)$ \\
1.Presentation & $2(4.9 \%)$ \\
Breech & $1(2.4 \%)$ \\
Face & $1(2.4 \%)$ \\
Transverse & $37(90.3 \%)$ \\
$\quad$ Vertex & \\
2. Birth weight $(\mathrm{kg})$ & $5(12.2 \%)$ \\
$<2.5$ & $33(80.5 \%)$ \\
$2.5-4$ & $3(7.3 \%)$ \\
$\geq 4$ & \\
3. Sex & $17(41.5 \%)$ \\
Female & $24(58.5 \%)$ \\
Male & \\
4. Start of breastfeeding & $36(87.8)$ \\
Within 1 hour & $2(4.9 \%)$ \\
$>1$ hour & $3(7.3 \%)$ \\
No breast feeding & \\
\hline
\end{tabular}

Low Apgar score $(<7)$ at one minute was noted in 8 $(19.5 \%)$ cases. Neonatal resuscitation in the form of oxygen supplementation was required in $2(4.9 \%)$ cases whereas bag and mask ventilation (BMV) was required in $5(12.2 \%)$ cases. Referral for NICU admission was done in $6(14.6 \%)$ cases. There were three NNDs each accounting for fresh still birth, NND within and after 24 hour of life (Table 5).

\begin{tabular}{|lc|}
\hline Table 5. Fetal complications. & \\
\hline Characteristics & $\mathbf{n}(\%)$ \\
1.Apgar score at $1 \mathrm{~min}$ & \\
$\quad>7 / 10$ & $33(80.5 \%)$ \\
$5-7 / 10$ & $4(9.8 \%)$ \\
$<5 / 10$ & $3(7.3 \%)$ \\
$0 / 10$ & $1(2.4 \%)$ \\
2.Neonatal resuscitation & \\
$\quad$ Not required & $34(82.9 \%)$ \\
Oxygenation & $2(4.9 \%)$ \\
Bag and mask ventilation & $5(12.2 \%)$ \\
3.Referral for NICU admission & $6(14.6 \%)$ \\
4.Neonatal injury during CS & - \\
5.Neonatal sepsis & $1(2.4 \%)$ \\
6.Neonatal seizure & $1(2.4 \%)$ \\
\hline
\end{tabular}

\begin{tabular}{|ll|} 
7.Neonatal death & $3(7.2 \%)$ \\
Fresh still birth & $1(2.4 \%)$ \\
NND within 24 hour of birth & $1(2.4 \%)$ \\
NND after 24 hour of birth & $1(2.4 \%)$ \\
\hline
\end{tabular}

\section{DISCUSSION}

The prevalence of emergency CS in this study was 5.5\% whereas it varied widely in different studies conducted by Onankpa et al $(8.4 \%),{ }^{10}$ Shah et al $(8.8 \%),{ }^{8}$ Nnadi et al $(11.3 \%),{ }^{1}$ Benzouina et al $(17.83 \%),{ }^{3}$ Elvedi-Gasparović $V$ et al $(18 \%),{ }^{11}$ Moges et al (27.6\%), ${ }^{4}$ McCarthy et al $(28.3 \%)^{12}$ and Hamilton et al $(32.2 \%) .^{13}$ The frequency of CS depends on the inherent obstetric population characteristics, socio-demographic pattern, hospital policy for referral, departmental protocols for managing cases of labour dystocia, breech, fetal distress, and previous CS, physician factor, risk of medico-legal conditions, number of babies required and maternal request (for painless delivery, sexual pleasure, fear of future pelvic organ prolapse and urinary incontinence in later life), use of electronic fetal monitoring and time given for conservative management in cases like fetal distress. ${ }^{4}$ Cesarean deliveries are not readily accepted by the mothers in some countries $^{10}$ and also liberal use of instrumental deliveries like vacuum or forceps explains low rate of cesarean deliveries. In this study, lower CS rate may be due to apparent under-utilization of a potentially lifesaving procedure due to inadequate health system resources ${ }^{8}$ i.e. lack of adequate manpower (surgeons, anesthetists and technical staffs), limited provision of CS per day even in case of need due to lack of equipments and post-operative wards and inefficient comprehensive emergency obstetric and newborn care program. This centre being near to capital, local women prefer referral on demand to hospitals of the valley.

In this study, CS in Primigravida accounted for $65.9 \%$ cases similar to studies by Bhandari $(63.6 \%),{ }^{14}$ and Adhikari et al $(55.48 \%),{ }^{15}$ but in contrast, it was $42 \%$, $38.95 \%, 36.4 \%$ and $24.8 \%$ respectively in studies by Kambo et al, ${ }^{16}$ Benzouina et $a{ }^{3},{ }^{3}$ Moges et al, ${ }^{4}$ and Nnadi et al. ${ }^{1}$ Higher CS rate in primigravida is due to common indications like fetal distress/cephalopelvic disproportion, maternal request, risk of medico-legal issues and limited resources/man-power for intrapartum monitoring leading to more liberal use of CS to deliver babies that are at high risk of intra-partum compromise $^{9}$ whereas in multipara higher CS rate is due to disproportion from fetal malposition and malpresentation along with high practice of elective repeat caesarean delivery as compared to trial of labour.

In this study, most common indication for CS was fetal distress in $29.3 \%$ cases which reciprocated with studies 
performed by Benzouina et $\mathrm{al}^{3} 30.49 \%$ and Bhandari ${ }^{14}$ 42.6\%. Contrary to above, it was CPD in studies by Shah et $\mathrm{al}^{8}$ and Moges et al $38.1 \%^{4}$; non-progression of labour (NPOL) in studies by Nnadi et al $25.7 \%{ }^{1}$ and Grace et al $37.4 \%{ }^{9}$; and obstructed labor in study by Ugwa et al $31.7 \% .{ }^{17}$ Rampant use of misoprostol leading to meconium stained liquor may result in fetal distress and in addition less priority may be given for conservative management of fetal distress leading to increased CS in such cases. Nutritional factors have dominant influence on pelvic shape and size; and malnutrition, which is still prevalent in developing countries especially during childhood, may have resulted in pelvic contraction and general growth stunting increasing the incidence of $\mathrm{CPD}$ resulting in increased $\mathrm{CS}$ rate. ${ }^{4}$

In the studies by Grace et $\mathrm{al}^{9}$ and Nnadi et $\mathrm{al}^{1}$ most common complication encountered was postpartum haemorrhage (PPH) with respective incidences of $1.49 \%$ and $7.94 \%$ which was comparable to this study was $4.9 \%$. In contrast to this, wound infection accounted in $2.1 \%$ in study by Bhandari ${ }^{14}$ and puerperal sepsis in $2.2 \%$ in study by Kalisa et al. ${ }^{18}$ High rate of PPH may be associated with uterine atonicity resulting from prolonged obstructed labor $^{1}$ and caesarean deliveries performed by resident doctors who are on training. Proper supervision and adequate attention to hemostasis along with liberal use of uterotonics and prostaglandins should be encouraged.

There were no cases of maternal mortality in this study whereas the maternal mortality was four per 1000 in study by Moges et $\mathrm{al}^{4}$ was 504 that is 19.8 per 1000 in study by Nnadi et al, ${ }^{1}$ the major culprit in later one being puerperal sepsis. Prolonged prelabour rupture of membrane ( $>18$ hours), multiple digital vaginal examinations without maintaining asepsis, late referral, restricted and injudicious use of antibiotics in these patients may be some of the many contributing factors for sepsis. Correct use of partograph in the peripheral health centers is of paramount importance as it would have detected labors deviating from the normal course and facilitated early referral even decreasing cases of puerperal sepsis from prolonged labor. ${ }^{1}$ In this study, reduced post-operative complications may be attributed to timely use of uterotonics, easy availability of blood and blood products, improved anaesthetic techniques and routine use of prophylactic antibiotics.

The sex ratio of male to female in this study was 1.4:1 as in the studies by Nnadi et al $(1.2: 1)^{1}$ and Benzouina et al $(1.1: 1){ }^{3}$ The relatively high number of male child may be attributed to illegal but increased sex selective abortion of female fetus.

In this study, Apgar score of $<7$ at one minute was noted in $19.5 \%$ cases which was comparable to study done by Grace et al ${ }^{9} 13.13 \%$. Another study by Bhandari ${ }^{14}$ reported Apgar score of $<5$ in $10.8 \%$ babies which was analogous to this study $(9.7 \%)$. Apgar score $<5$ was noted in $52.43 \%$ cases by Nnadi et al. ${ }^{1}$ In a study by Benzouina et $\mathrm{al}^{3}$, birth asphyxia was observed in $4.04 \%$ newborns.

The perinatal mortality was 73.17 per 1000 , most commonly due to birth asphyxia in our cases. The primary etiology was similar to that of study by Moges et al. ${ }^{4}$ The incidence of perinatal mortality varied from 446 that is 13.5 per 1000 to 288 that is 119.1 per 1000 in studies by Benzouina et $\mathrm{al}^{3}$ and Nnadi et al ${ }^{1}$ respectively. The national perinatal mortality is 31 per 1000 as per Nepal demographic and health survey. ${ }^{6}$ Likewise, Onankpa et al $^{10}$ stated perinatal mortality to be 11 per 1000 among the caesarean deliveries. Contrary to this, there were no perinatal deaths reported in study by Grace et al. ${ }^{9}$ High perinatal mortality may have occurred due to suboptimal care resulting from insufficient and untrained human resources that are required for intra-partum fetal surveillance by monitoring fetal heart sound (FHS), laboratory services for fetal scalp blood sampling and operating equipments like cardiotocography (CTG) and ultrasonography (USG) to recognize signs of developing fetal compromise. Despite timely detection of fetal compromise, referral to centers in capital is not easy due to topographical difficulties and jammed highway. The other reason adding up to perinatal mortality is CS done for fetal distress in moribund state.

There is emerging evidence that in term, appropriately grown babies, the cerebro-umbilical ratio and umbilical venous flow rate ${ }^{19,20}$ may be helpful in identifying pregnancies at risk of intra-partum compromise requiring emergency CS for delivery. It has recently been demonstrated that the likelihood of death on the day of birth exceeds that of any other day until the tenth decade of life. ${ }^{21}$ This hospital also serves as referral centre for sub-health posts, health post and primary health care centres of Dhading district and it is established fact that overall maternal mortality and stillbirths are high in facilities receiving many referrals. High emergency cesarean delivery rates were associated with increased fresh stillbirths, NNDs and severe neonatal morbidity. Majority of emergency CS performed for labour dystocia and fetal distress resulted in a significant proportion of the perinatal deaths. Severe newborn morbidity was related to birth asphyxia secondary to prolonged labor and late interventions to prevent perinatal morbidity and mortality. Close monitoring of labor, early detection of complications and timely decision for caesarean delivery are crucial. ${ }^{8}$

Since it was a hospital based study, all data for long term follow-up could not be presented. The time 
duration of study was less considering the volume of deliveries and caesarean sections.

The good part of this study is that it has highlighted the status regarding health delivery system of district hospitals of the country in terms of maternal and fetal outcomes and has provided chances for improvement. This study could be prolonged to know the facts and figures better.

\section{CONCLUSIONS}

Residential posting was fruitful to decrease maternal and fetal morbidities and mortalities as compared to records of previous years. Emergency CS should be performed uninterruptedly and in liberal way as per valid indications to improve maternal and fetal outcomes. To uplift the figure in terms of maternal and fetal status, it is essential to minimize the delay in treatment by improving transportation facilities and setting up NICU and maternal ICU services with adequate skilled manpower at local level. Residents should be posted at district hospital to supplement the specialist and not to replace them. Government should be aware that residents should work under supervision of seniors and should not be employed as specialist to fill the vacuum. Residential posting should not avoid creating necessary vacancies of specialist doctors.

\section{ACKNOWLEDGEMENTS}

I would like to acknowledge Dr Dibya Poudel for her help during data collection and Dr Shraddha Rana for her contribution in correcting grammatical errors of this manuscript.

Conflict of Interest: None.

\section{REFERENCES}

1. Nnadi DC, Singh S, Ahmed $Y$, Siddhique S, Bilal S Maternal and fetal outcomes following cesarean deliveries: A cross-sectional study in a tertiary health institution in north-western Nigeria. Sahel Medical Journal. 2016;19(4):175-9. [FullText | DOI]

2. Cunningham FG, Lenevo KJ, Bloom SL, Spong CY, Dashe JS, Hoffman BL, editors et al. Caesarean delivery and peripartum hysterectomy. Williams obstetrics. $24^{\text {th }}$ ed. New York: Mc Graw Hill Education. 2014;587-608. [FullText]

3. Benzouina S, Boubkraoui MEM, Mrabet M, Chahid N Kharbuch A, El-hassani A et al. Fetal outcome in emergency versus elective cesarean section at Souissi maternity hospital Rabot, Morocco. Pan Afr Med J. 2016 Apr 15;23:197. [Pub Med | FullText | DOI]

4. Moges A, Ademe BW, Akessa GM. Prevalence and outcome of caesarean section in Attat hospital, Gurage zone, SNNPR, Ethiopia. iMedPub Journals. 2015;7(4:8);1-6. [FullText]

5. Betran AP, Torloni MR, Zhang JJ, Gülmezoglu AM, Aleem HA, Althabe F et al. World Health Organization statement on caesarean section rates. BJOG. 2016 Apr;123(5):667-70. [PubMed | FullText | DOI]

6. Ministry of Health. Delivery services. Nepal Demographic and Health Survey 2016. 2017 Nov:156. [FullText]

7. Litorp H, Roost M, Kidanto HL, Nystrom L, Essen B. The effects of previous cesarean deliveries on severe maternal and adverse perinatal outcomes at a university hospital in Tanzania. International Journal of Gynecology and Obstetrics. 2016;133:183-7. [FullText | DOI]

8. Shah A, Fawole B, M'Imunya JM, Amokrane F, Nafiou I, Wolomby JJ et al. Caesarean delivery outcomes from the WHO global survey on maternal and perinatal health in Africa. Int J Gynecol Obstet. 2009;1-9. [라Med | FullText | DOI]
9. Grace L, Greer RM, Kumar S. Perinatal consequenes of a category 1 caesarean section at term. 2018 Feb 24. [․ㅏllText | DOI]

10. Onankpa B, Ekele B. Fetal outcome following cesarean section in a university teaching hospital. J Natl Med Assoc. 2009 Jun;101(6):578-1. [PubMed | FullText]

11. Elvedi-Gasparović V, Klepac-Pulanić T, Peter B. Maternal and fetal outcome in elective versus emergency caesarean section in a developing country. Coll Antropol. 2006 Mar;30(1):113-8. [PubMed | FullText]

12. McCarthy FP, Rigg L, Cady L, Cullinane F. A new way of looking at caesarean section births. Aust N Z J Obstet Gynaecol. 2007 Aug;47(4):316-20. [P PubMed | FullText | $\underline{\mathrm{DOI}}]$

13. Hamilton BE, Martin JA, Osterman MJ, Curtin SC. Births: Preliminary data for 2014. National Vital Statistics Reports. 2015 Jun;64(6):1-19. [PubMed | FullText]

14. Bhandari BR. Maternal and fetal outcomes following caesarean section in comprehensive emergency obstetric care program at Nuwakot district hospital. NJOG. 2015;20(2):40-4. [FullText]

15. Adhikari S, Dasgupta M, Sanghamita M. Management of obstructed labor: a retrospective study. Obstet Gynecol India. 2005;55(1):48-51. [․ullText]

16. Kambo I, Bedi N, Dhillon BS, Saxena NC. A critical appraisal of cesarean section rates at teaching hospitals in India. Int J Gynaecol Obstet. 2002 Nov;79(2):151-8. [PubMed | FullText]

17. Ugwa EA, Ashimi AO, Abubakar MY. Caesarean section and perinatal outcome in a sub-urban tertiary hospital in northwest Nigeria. NJOG. 2015;20(2):29-32. [ FullText | DOI] 
18. Kalisa R, Rulisa S, Roosmalen Jv, Akter Tvd. Maternal and perinatal outcome after previous caesarean section in rural Rwanda. BMC Pregnancy and Childbirth. 2017;17:272. [PubMed $\mid$ FullText $\mid \underline{\text { DOI] }}$

19. Prior T, Mullins E, Bennett P, Kumar S. Prediction of intrapartum fetal compromise using the cerebroumbilical ratio: a prospective observational study. Am J Obstet Gynecol. 2013 Feb;208(2):124.e1-6. [PubMed | FullText | DOI]
20. Prior T, Mullins E, Benett $P$, Kumar S. Umbilical venous flow rate in term fetuses: can variations in flow predict intrapartum compromise? Am J Obstet Gynecol. 2014 Jan;210:61.e1-8. [FullText | DOI]

21. Walker KF, Cohen AL, Walker SH, Allen KM, Baines DL, Thornton JG. The dangers of the day of birth. BJOG. 2014 May;121(6):714-8. [FullText | DOI] 